\title{
DESIGN AND DEVELOPMENT OF MONTELUKAST SODIUM FAST DISSOLVING FILMS FOR BETTER THERAPEUTIC EFFICACY
}

\author{
PRABHAKAR VISHVAKARMA*
}

Pharmaceutics Research Lab, Vivek College of Techncal Education, Bijnor

\begin{abstract}
The oral route is most popular route for the administration of therapeutic agents because of the low cost of therapy and ease of administration lead to high levels of patient compliance. The most popular oral solid dosage forms are tablets and capsules. Many patients find it difficult to swallow tablets and hard gelatin capsules particularly pediatric and geriatric patients and do not take their medicines as prescribed. The objective of this research was to prepare fast dissolving oral thin film (FDOTF) containing Montelukast sodium is indicated for the prophylaxis and chronic treatment of asthma to enhance convenience and compliance to the elderly and pediatric patients for better therapeutic efficacy. The present investigation was undertaken with the objective of formulating of the montelukast sodium fast dissolving oral thin films allowing fast reproducible drug dissolution in oral cavity thus bypassing first pass metabolism. The film were prepared by using polymers such as hydroxypropyl methyl cellulose (HPMC) and Maltodextrin, plasticizer such as PEG 400, by a solvent casting method. They were evaluated for physical characteristics such as thickness, uniformity of weight, folding endurance, drug content, surface ph, percentage elongation and tensile strength, drug polymers compatibility by FTIR study, scanning electron microscopy and in vitro drug release. The formulations were subjected to disintegration, in-vitro drug release test. The in vitro disintegration time of the optimized batch F4 was found to be 20 sec. The optimized batch was found to be stable for 1 month under specified stability conditions.
\end{abstract}

Keywords: BisoprololFumarate, Fast dissolving film, HPMC, Maltodextrin, Solvent casting method, $3^{2}$ factorial. The formulations were subjected to disintegration, in-vitro drug release test. The in vitro disintegration time of the optimized batch F4 was found to be 20 sec. The optimized batch was found to be stable for 1 month under specified stability conditions.

\section{INTRODUCTION}

Among the different routes, the most agreeable route for the patients is oral route. Most of the pharmaceutical companies have directed their search activity in developing viable dosage alternatives from oral route for pediatrics, geriatric, noncompliant or nauseous patients. Research in the oral drug delivery segment has led to evolution of dosage forms from simple conventional tablets/ capsules to modified release tablets/capsules to oral disintegrating tablet to wafer to the recent development of fast dissolving oral films. Fast dissolving oral film, a novel drug delivery system for the oral delivery of the drugs is an ultra-thin film prepared using hydrophilic polymers that rapidly dissolves on the top or the floor of the tongue or buccal cavity. It is an ultrathin $\operatorname{strip}(50-150$ microns thick) of postage stamp size with an active agent and other excipients developed on the basis of transdermal patch technology. ${ }^{1,2,3}$ Fast-dissolving drug-delivery systems were first developed in the late 1970s as an alternative to tablets, capsules, and syrups for pediatric and geriatric patients who experience difficulties swallowing traditional oral solid-dosage forms. The novel technology of oral fast-dispersing dosage forms is known as fast dissolve, rapid dissolve, rapid melt and quick disintegrating tablets. However, the function and concept of all these dosage forms are similar. By definition, a solid dosage form that dissolves or disintegrates quickly in the oral cavity, resulting in solution or suspension without the need for the administration of water, is known as an oral fast-dispersing dosage form. Difficulty in swallowing (dysphagia) is common among all age groups, especially in elderly, and is also seen in swallowing conventional tablets and capsules ${ }^{4}$. An estimated $35 \%$ of the general population, and an additional $30.40 \%$ of elderly institutionalized patients and $18.22 \%$ of all persons in long-term care facilities, suffer from dysphagia. This disorder is associated with many medical conditions, including stroke, Parkinson's, AIDS, thyroidectomy, head and neck radiation therapy, and other neurological disorders, including cerebral palsy. ${ }^{5,6}$ One study showed that $26 \%$ of 1576 patients experienced difficulty in swallowing tablets. The most common complaint was tablet size, followed by surface, form and taste. The problem of swallowing tablets was more evident in geriatric and pediatric patients, as well as traveling patients who may not have ready access to water. ${ }^{7,8}$ Formulation of these systems is usually straightforward; the polymer and drug are dissolved in a solvent and a film is cast by solvent evaporation. ${ }^{9,10}$ Most commercially available oral thin formulations, such as Oral film TM, (benzocaine) or Theraflu ${ }^{\circledR}$, (dextromethorphan/ Phenylephrine $\mathrm{HCl}$ or Diphenhydramine $\mathrm{HCl}$ ) are designed to deliver locally acting drugs or for mouth-freshening (such as Listerine Pocket Paks TM, ). Montelukast sodium is a leukotriene receptor antagonist (LTRA) used in maintenance treatment of asthma and to relieve symptoms ofseasonal allergies. ${ }^{11}$ It is usually administered orally. Montelukast blocks the action of leukotriene D4 on the cysteinyl leukotriene receptor CysLT1 in lungs and bronchial tubes by binding to it. This reduces the bronchoconstriction otherwise caused by the leukotriene, and results in less inflammation. Montelukast sodium bioavailability is $63 \%$. It has extensive first-pass metabolism and show a very poor dissolution rates in order to overcome this problem preparation of oral thin films. The main objectives of the present study were to prepare and evaluate the oral thin films of montelukast sodium and to study the various formulation variables that affect in vitro performance. ${ }^{12,13}$

\section{Criteria for Fast Dissolving Film ${ }^{14,15}$ :}

Fast dissolving film should

- $\quad$ Have a pleasant mouth feel.

- $\quad$ Not require water to swallow, but it should dissolve or disintegrate in the mouth in matter of seconds.

- $\quad$ Be compatible with taste masking

- Leave minimum or no residue in the mouth after oral administration.

- Exhibit low sensitivity to environmental conditions such as temperature and humidity.

- Allow the manufacture of the tablet using conventional processing and packaging equipmentsat low cost.

Advantages of FDF $^{16,17}$ :

- $\quad$ Ease of administration to pediatric, geriatric, bedridden patients and psychiatric patients who refuse to swallow tablets.

- No need of water to swallow the dosage form, which is highly convenient feature for patients who are traveling

- $\quad$ Rapid dissolution and absorption of drug, which may produce rapid onset of action.

- $\quad$ Some drugs are absorbed from the mouth, pharynx and esophagus as the saliva passes down into the stomach, which enhances bioavailability of drugs.

- $\quad$ Pregastric absorption can result in improved bioavailability and as a result of reduced dosage; improved clinical performance through a reduction of unwanted effects.

- Good mouth feel property helps to change the perception of medication as bitter pill particularly in pediatric patient.

- The risk of chocking or suffocation during oral administration of conventional formulation due to physical obstruction is avoided, thus providing improved safety.

- Useful in cases where an rapid onset of action required such as in motion sickness, sudden episodes of allergic attack or coughing, bronchitis or asthma.

- An increased bioavailability, particularly in cases of insoluble and hydrophobic drugs, due to rapid disintegration and dissolution of these tablets. 
- Stability for longer duration of time, since the drug remains in solid dosage form till it is consumed. So, it combines advantage of solid dosage form in terms of stability and liquid dosage form in terms of bioavailability. ${ }^{18}$

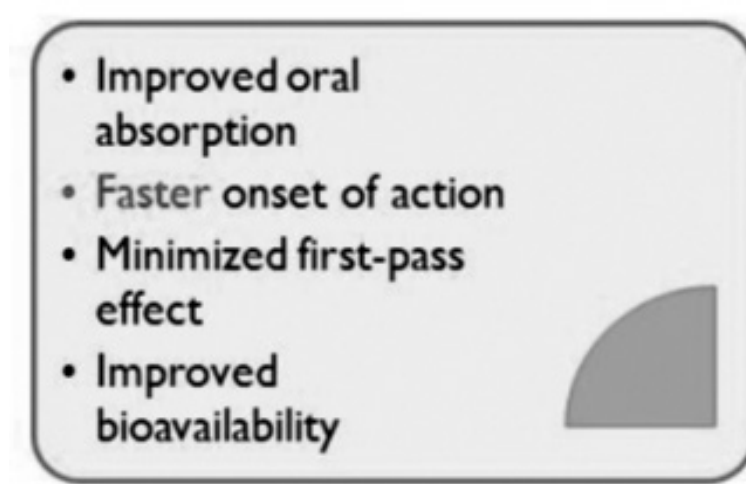

- Oral mucosa highly vascularised.

- Consume at anyplace at anytime....
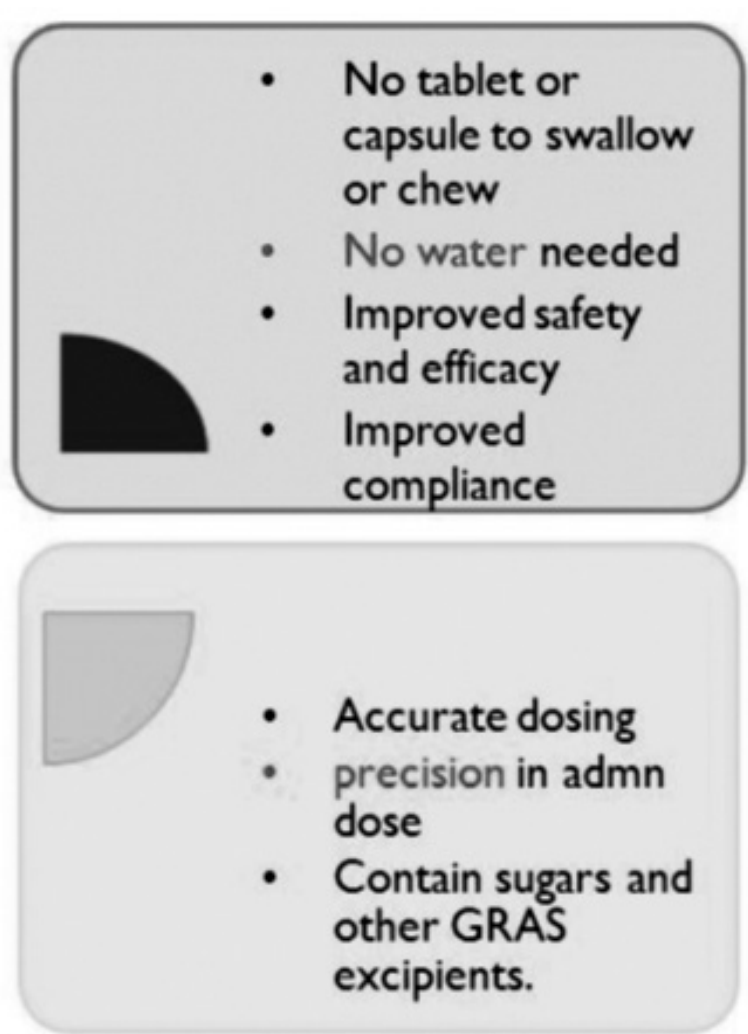

\section{MATERIALS AND METHODS}

Materials

Montelukast sodium was received as a gift sample from Hetero Drugs, Hyderabad India. HPMC E5, E15, Maltodextrin was obtained from Lupin Research Park (Lupin Ltd). PEG 400, glycerin, aspartame, PVA was obtained from Research Lab Fine Chem Industries, Mumbai, India. Poonam A. Padamwar et al. / International Journal of Pharma Sciences and Research (IJPSR)

\section{METHODS}

Preparation of montelukast sodium oral thin films by Using $3^{2}$ Full Factorial Designs

The fast dissolving oral film of the Montelukast sodium by using HPMC E15 and Maltodextrin is prepared by solvent casting method. In this first aqueous solution of the HPMC E15 and Maltodextrin is prepared by dissolving the HPMC E15 and Maltodextrin in distilled water. Montelukast sodium is added to the aqueous solution after that citric acid is added to the above solution followed by addition of the sweetener (Aspartame) and plasticizer. ${ }^{19}$ The solution was casted on the casting surface (mould, Petri dish) and dried at room temperature for 10 hours or dried into a Hot air oven for $6 \mathrm{hrs}$. Then film removed from the surface and cut into the desired size $(2 \times 2)$ of equivalent dose of Montelukast sodium. This preparation method was followed till completion of work. ${ }^{20}$

\section{EVALUATION OF FAST DISSOLVING ORAL THIN FILM}

Weight Variation ${ }^{21}$

The weight variation test is determined by measuring the weight of the individual film of $2 \mathrm{~cm} \times 2 \mathrm{~cm}$ area. For the measurement of the weight digital analytical balance was used. The weight of three films was measure and mean is taken.
Thickness $^{21}$

The thickness of strip was measured by digital vernier caliper at different locations. This is essential to ascertain uniformity in the thickness of the film as this is directly related to the accuracy of dose in the strip.

\section{Folding endurance ${ }^{21}$}

Folding endurance is determined by repeated folding of the strip at the same place till the strip breaks. The number of times the film is folded without breaking is computed as the folding endurance value.

Tensile strength ${ }^{22}$

Tensile strength of films was determined using an apparatus fabricated in laboratory. A small film strip $(2 \times 2 \mathrm{~cm} 2)$ was cut and fixed to assembly. The weight required to break the film was noted and simultaneously film elongation was measured with the help of pointer mounted on the assembly. Measurements were done in triplicate for each batch. The mechanical properties tensile strength and \% elongation were calculated for the fast dissolving film from the above measurements. Tensile strength is the ratio of maximum stress applied to a point at which the film specimen breaks and can be computed from the applied force at rupture to the cross sectional area of the fractured film as a mean of three measurements and described in the equation- 


\begin{tabular}{|c|c|c|}
\hline Formulation code & Variable level & \\
\hline & X1(Polymer) & X2(Plasticizer) \\
\hline F1 & -1 & -1 \\
\hline F2 & -1 & 0 \\
\hline F3 & -1 & +1 \\
\hline F4 & 0 & -1 \\
\hline F5 & 0 & 0 \\
\hline F6 & 0 & +1 \\
\hline F7 & +1 & -1 \\
\hline F8 & +1 & 0 \\
\hline F9 & +1 & +1 \\
\hline
\end{tabular}

\begin{tabular}{|c|c|c|c|c|c|c|c|c|c|}
\hline & F1 & F2 & F3 & F4 & F5 & F6 & F7 & F8 & F9 \\
\hline DRUG (mg) & 10 & 10 & 10 & 10 & 10 & 10 & 10 & 10 & 10 \\
\hline HPMC + & 400 & 400 & 400 & 400 & 400 & 400 & 400 & 400 & 400 \\
MALTODEXTRIN (mg) & +50 & +100 & +150 & +50 & +100 & +150 & +50 & +100 & +150 \\
\hline PEG 400 (mg) & 50 & 50 & 50 & 60 & 60 & 60 & 70 & 70 & 70 \\
\hline ASPARTAME (mg) & 50 & 50 & 50 & 50 & 50 & 50 & 50 & 50 & 50 \\
\hline CITRIC ACID (mg) & 18 & 18 & 18 & 18 & 18 & 18 & 18 & 18 & 18 \\
\hline MENTHOL & q.s & q.s & q.s & q.s & q.s & q.s & q.s & q.s & q.s \\
\hline COLOUR & q.s & q.s & q.s & q.s & q.s & q.s & q.s & q.s & q.s \\
\hline WATER (mI) & 10 & 10 & 10 & 10 & 10 & 10 & 10 & 10 & 10 \\
\hline
\end{tabular}
Width

Tensile strength $=$ Load at failure $x 100 \backslash$ Strip Thickness $X$ Strip

\section{Percent elongation ${ }^{22}$}

When stress is applied, a strip sample stretches and this is referred to as strain. Strain is basically the deformation of strip divided by original dimension of the sample. Generally elongation of strip increases as the plasticizer content increases. of strip

$\%$ Percent elongation $=$ Increase in length of strip $X 100 \backslash$ Initial length

\section{pH Value $e^{23}$}

The $\mathrm{pH}$ value can determine by dissolving one oral film in $10 \mathrm{ml}$ distilled water and measuring the $\mathrm{pH}$ of the obtained solution. It is necessary that film should have nearly uniform $\mathrm{pH}$ value.

\section{Drug content ${ }^{23}$}

For determination of the drug content Montelukast sodium oral film equivalent to dose of $2.5 \mathrm{mg}$ was dissolved in $50 \mathrm{ml}$ of pH 6.8 buffer . The solution was sonicated for 10 minutes and then filtered through Whatman filter paper no. 41 , to separate out the insoluble excipients. $1 \mathrm{ml}$ of filtrate was diluted to $100 \mathrm{ml}$ with $\mathrm{pH} 6.8$ buffer. The absorbance of resultant solution was measured using $\mathrm{U}$. V. spectrophotometer at $285 \mathrm{~nm}$ and drug content was calculated.

\section{Disintegration time ${ }^{23}$}

The disintegration for orally disintegrating tablets described in CDER guidance can be applied to oral film. Although, no official guidance is available for FDOF, this may be used as a qualitative guideline for quality control test or at development stage. But for the present work disintegration was measured by taking the $25 \mathrm{ml}$ of distilled water in $50 \mathrm{ml}$ beaker and individual film is dipped into that solution and disintegration time was recorded.

Surface texture ${ }^{24}$

Surface texture was evaluated by visual appearance of oral film and categorized in smooth to rough surface indicates by mathematical + sign.
Moisture absorption ${ }^{24}$

The film sample is weighed and placed on a pre-weighed stainless steel wire mesh. The wire mesh is then submerged in a Petridis containing $20 \mathrm{~m}$ distilled water. Increase in weight of the film is determined at regular time intervals $(10 \mathrm{~min})$ until a constant weight is obtained the hydration ratio of the film is calculated and average moisture absorption is calculated and reported.

\section{Hydration ratio $=\mathrm{Wt}-\mathrm{W} 0 \times 100 / \mathrm{W0}$}

Where $\mathrm{Wt}=$ weight of film at time $\mathrm{t}$ and $\mathrm{W} 0=$ weight of film at zero time.

Moisture loss ${ }^{24}$

The percent moisture loss was determined by placing prepared film in desiccators containing anhydrous calcium chloride. After three days, the film was taken and reweighed. Average percent moisture loss was calculated.

Moisture loss $=$ W0/W0-Wt $\times 100$

\section{Content uniformity}

The content uniformity test was used to ensure that every film contains the intended amount of drug substance with little variation among films within a patch. Three pieces, each $6 \mathrm{~cm} 2(3 \times 2 \mathrm{~cm})$, were cut from the whole patch, and assayed for drug content. Same procedure was repeated for all the nine batches.

\section{In Vitro Dissolution study ${ }^{2}$}

The in vitro release of drug from all formulations was determined using USP apparatus type II (Paddle method). The following conditions were followed to study the in-vitro dissolution study of Montelukast sodium Ora Film.

1. USP dissolution apparatus: Type II (Paddle method)

2. Volume of dissolution medium: $900 \mathrm{ml}$

3. Speed: $50 \mathrm{rpm}$

4. Temperature: $37 \pm 0.50 \mathrm{C}$

5. Dissolution medium: $\mathrm{pH} 6.8$ buffer

6. Sampling interval: $1 \mathrm{~min}$

7. Quantity of sample withdrawn: $5 \mathrm{ml}$

Aliquots of dissolution medium of $5 \mathrm{ml}$ were withdrawn at 1 min interval for $4 \mathrm{~min}$. The volume withdrawn was replaced by fresh volume of dissolution medium. The filtered samples were analyzed spectrophotometrically at $285 \mathrm{~nm}$ and absorbance was noted. Cumulative percent drug release was calculated. 


\section{RESULTS}

FT -IR Compatibility Study

Compatibility of drug and polymers was studied using Fourier Transform Infrared (FTIR) spectroscopy. FTIR Spectrum was recorded between 600$4000 \mathrm{~cm}-1$ using Shimadzu 160a, Kyoto, Japan by KBrDisc method.The FTIR spectra of montelukast sodium and its physical mixtures are shown in figure 2 . The FTIR spectrum of montelukast depicts a characteristic absorption band at
$3437 \mathrm{~cm}^{-1}$ representing the presence of $\mathrm{OH}$ group. The $\mathrm{CH}, \mathrm{C}-\mathrm{N}$ vibrations showed a characteristic absorption band in the region of $2926 \mathrm{~cm}-1$ and 1265 $\mathrm{cm}-1$. The spectrum of montelukast- polymer physical mixtures showed absorption bands at $3414 \mathrm{~cm}-1,2926 \mathrm{~cm}-1$ and $1266 \mathrm{~cm}-1 \mathrm{OH}$, The $\mathrm{CH}_{2}$ and $\mathrm{C}-\mathrm{N}$. It indicates drug and drug containing physical mixture absorption bands were near that there was no chemical and physical change in the functional groups present in montelukast sodium.

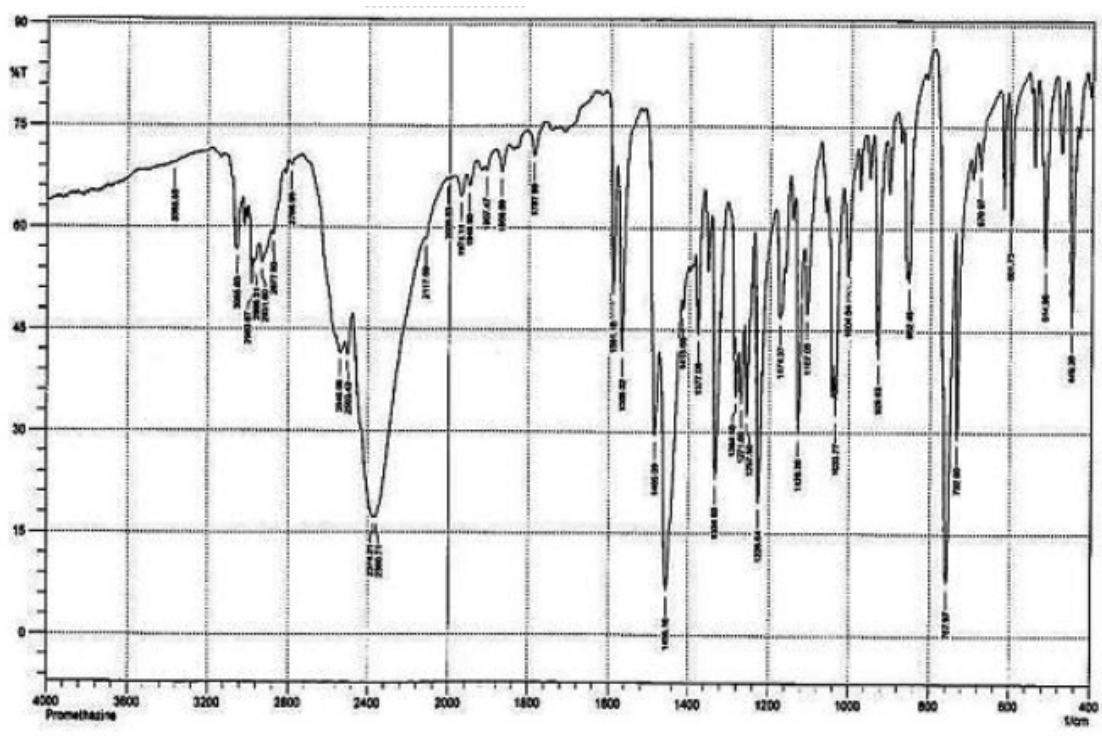

Figure 2: FT- IR spectra of a) Montelukastsodium , b) HPMC E 50 lv, c) HPMC e 15 lv, d) physical mixture of polymers and Montelukast sodium.

Table 1. Evaluation of physico-mechanical parameters of fast dissolving film.

\begin{tabular}{|c|c|c|c|c|c|c|}
\hline Formulation & Transparency & $\begin{array}{c}\text { Weight variation } \\
\text { (mg) }\end{array}$ & $\begin{array}{c}\text { Thickness } \\
\text { (mm) }\end{array}$ & $\begin{array}{l}\text { Tensile strength } \\
\left(\mathrm{kg} / \mathrm{Cm}^{2}\right)\end{array}$ & Folding Endurance & Surface $\mathbf{p H}$ \\
\hline F1 & Good & $24.56 \pm 0.09$ & $0.26 \pm 0.021$ & $0.609 \pm 0.019$ & $75 \pm 0.23$ & $6.59 \pm 0.029$ \\
\hline F2 & Best & $22.21 \pm 0.20$ & $0.24 \pm 0.030$ & $0.623 \pm 0.021$ & $77 \pm 0.12$ & $6.61 \pm 0.025$ \\
\hline F3 & Best & $20.19 \pm 0.17$ & $0.30 \pm 0.071$ & $0.603 \pm 0.024$ & $85 \pm 0.19$ & $7.05 \pm 0.004$ \\
\hline F4 & Best & $22.11 \pm 0.11$ & $0.20 \pm 0.020$ & $2.679 \pm 0.065$ & $78 \pm 0.34$ & $6.91 \pm 0.021$ \\
\hline F5 & Good & $23.12 \pm 0.12$ & $0.30 \pm 0.071$ & $0.639 \pm 0.024$ & $79 \pm 0.16$ & $6.54 \pm 0.021$ \\
\hline F6 & Best & $20.15 \pm 0.24$ & $0.24 \pm 0.01$ & $2.435 \pm 0.046$ & $79 \pm 0.36$ & $6.89 \pm 0.023$ \\
\hline F7 & Good & $20.12 \pm 0.12$ & $0.25 \pm 0.006$ & $0.629 \pm 0.062$ & $71 \pm 0.81$ & $6.69 \pm 0.028$ \\
\hline F8 & Best & $21.22 \pm 0.35$ & $0.25 \pm 0.015$ & $2.120 \pm 0.032$ & $76 \pm 0.45$ & $6.48 \pm 0.027$ \\
\hline F9 & Good & $22.23 \pm 0.31$ & $0.17 \pm 0.006$ & $0.631 \pm 0.017$ & $73 \pm 0.42$ & $6.56 \pm 0.024$ \\
\hline
\end{tabular}

Table 2. Evaluation of physico-mechanical parameters of fast dissolving film.

\begin{tabular}{|c|c|c|c|c|c|}
\hline Formulation & Surface texture & $\begin{array}{l}\% \text { Moisture } \\
\text { absorption }\end{array}$ & $\%$ Moisture loss & $\%$ Drug content & $\begin{array}{c}\text { In vitro disintegration } \\
\text { time (s) }\end{array}$ \\
\hline F1 & ++- & $3.9 \pm 0.47$ & $2.97 \pm 0.33$ & $96.15 \pm 0.78$ & $21.3 \pm 1.25$ \\
\hline F2 & ++- & $2.4 \pm 0.54$ & $3.32 \pm 0.09$ & $90.34 \pm 0.12$ & $16.3 \pm 1.17$ \\
\hline F3 & ++- & $3.9 \pm 0.72$ & $3.47 \pm 0.12$ & $92.48 \pm 0.32$ & $12.6 \pm 1.13$ \\
\hline F4 & +++ & $3.7 \pm 0.99$ & $2.99 \pm 0.12$ & $98.55 \pm 0.34$ & $09.7 \pm 1.12$ \\
\hline F5 & +++ & $3.8 \pm 0.67$ & $2.10 \pm 0.89$ & $95.76 \pm 0.45$ & $13.5 \pm 1.10$ \\
\hline F6 & ++- & $4.5 \pm 0.54$ & $3.93 \pm 0.14$ & $97.41 \pm 0.54$ & $12.5 \pm 1.14$ \\
\hline F7 & ++- & $4.2 \pm 0.49$ & $3.43 \pm 0.12$ & $97.01 \pm 0.51$ & $15.5 \pm 1.09$ \\
\hline F8 & +++ & $4.6 \pm 0.34$ & $3.10 \pm 0.12$ & $94.89 \pm 0.72$ & $17.4 \pm 1.33$ \\
\hline F9 & ++- & $4.7 \pm 0.77$ & $3.45 \pm 0.13$ & $96.90 \pm 0.70$ & $14.7 \pm 1.02$ \\
\hline
\end{tabular}

(+) Indicates Smooth Surface, (-) Indicate Rough Surface 
J. Chil. Chem. Soc., 63, Nº 2 (2018)

Table 3. Cumulative \% Drug release of formulation F1 to F9.

\begin{tabular}{|c|c|c|c|c|c|c|c|c|c|}
\hline Time & F1 & F2 & F3 & F4 & F5 & F6 & F7 & F8 & F9 \\
\hline 0 min & $0 \%$ & $0 \%$ & $0 \%$ & $0 \%$ & $0 \%$ & $0 \%$ & $0 \%$ & $0 \%$ & $0 \%$ \\
\hline $1 \min$ & $27 \%$ & $28.5 \%$ & $28.5 \%$ & $34.5 \%$ & $25.5 \%$ & $27 \%$ & $25 \%$ & $26.85 \%$ & $24.45 \%$ \\
\hline $2 \min$ & $49.5 \%$ & $69 \%$ & $73.5 \%$ & $63 \%$ & $57 \%$ & $66 \%$ & $60.5 \%$ & $68.55 \%$ & $64.5 \%$ \\
\hline $3 \min$ & $94.35 \%$ & $96 \%$ & $96.3 \%$ & $99 \%$ & $96.75 \%$ & $97.35 \%$ & $94.2 \%$ & $97.95 \%$ & $98.85 \%$ \\
\hline
\end{tabular}

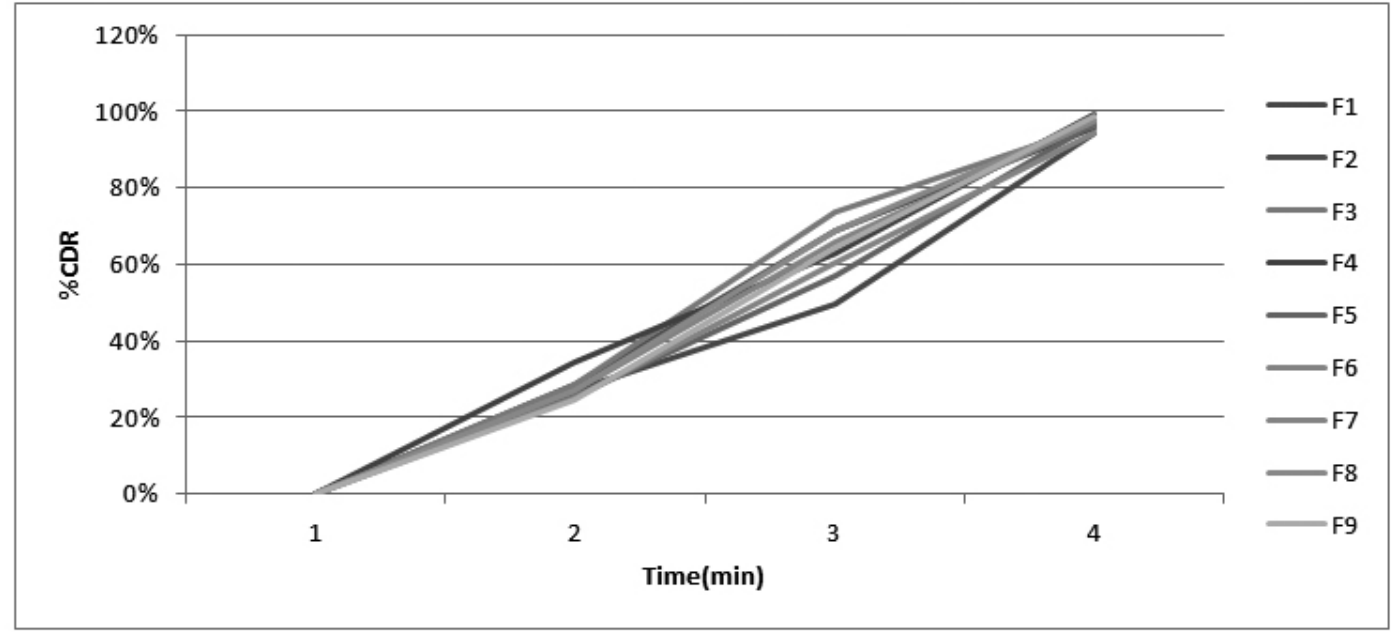

Figure 3: invitrodissolution profile for oral thin films of Montelukast sodium.

The in-vitro drug release from film of all formulation was performed in triplicate using USP apparatus II (paddle method). Dissolution study was performed in $\mathrm{pH} 6.8$ phosphate buffer. In case of $\mathrm{F} 4$ and $\mathrm{F} 9$ formulations about $99 \%$ and $98.85 \%$ of drug was released in 3 min. In case of F1, F7 formulation about $94.35 \%$ and $94.2 \%$ of drug released in $3 \mathrm{~min}$. This drug release pattern indicates that the increased concentration of polymer decreases drug release and increased concentration of plasticizer increases drug release.

Accelerated stability study of optimized batch:

Stability of a drug has been defined as the ability of a particular formulation in a specific container, to remain within its physical, chemical, therapeutic and toxicological specifications. The purpose of stability study is to provide evidence on the quality of a drug substance or drug product which varies with time under the influence of a variety of environmental factors such as temperature, humidity and light. Recommended storage conditions, re-test periods and shelf lives are to be established. The International Conference of Harmonization (ICH) Guidelines titled, "stability testing of New Drug substance and products" (QIA) describes the stability testrequirements for drug registration application in the European Union, Japan and the United States of America.

ICH specifies the length of study and storage conditions

Long-term testing: - $250 \mathrm{C} \pm 20 \mathrm{C} / 60 \% \mathrm{RH} \pm 5 \%$ for 12 months.

Accelerated testing: - $400 \mathrm{C} \pm 20 \mathrm{C} / 75 \% \mathrm{RH} \pm 5 \%$ for 6 months.

Accelerated Stability studies were carried out at $400 \mathrm{C} / 75 \% \mathrm{RH}$ for the best formulations for 1 month.

Method: The best formulation was assessed their accelerated stability with respect to their appearance, in-vitro disintegration time, surface $\mathrm{pH} \&$ drug release characteristics after storing them at $40 \pm 20 \mathrm{C} / 75 \pm 5 \% \mathrm{RH}$ for 1 month.

Table 4. Results of Accelerated stability study.

\begin{tabular}{|c|c|c|c|c|c|c|}
\hline Batch & Appearance & $\begin{array}{c}\text { Folding } \\
\text { Endurance }\end{array}$ & Weight (Mg) & $\begin{array}{c}\text { DisintegrationTime } \\
\text { (Sec) }\end{array}$ & Tensile Strength(kg/Cm²) & $\begin{array}{c}\text { \%Drug } \\
\text { Content }\end{array}$ \\
\hline Initial & Transparent & $78 \pm 0.34$ & 31.38 & $09.7 \pm 1.12$ & $2.679 \pm 0.065$ & $98.55 \pm 0.34$ \\
\hline $\begin{array}{c}\text { After 1 } \\
\text { Month }\end{array}$ & Transparent & $80 \pm 0.26$ & 29.23 & $11.2 \pm 1.08$ & $2.158 \pm 0.043$ & $97.22 \pm 0.12$ \\
\hline
\end{tabular}

Table 5. in vitro drug release profile of F4 batch after accelerated stability study.

\begin{tabular}{|c|c|c|}
\hline Time ( min) & Initial & After 1 Month \\
\hline 0 & $0 \%$ & $0 \%$ \\
\hline 0.5 & $34.5 \%$ & $31.04 \%$ \\
\hline 1.5 & $63 \%$ & $60.3 \%$ \\
\hline 2.5 & $99 \%$ & $97 \%$ \\
\hline
\end{tabular}




\section{CONCLUSION}

In current research work, an effort has been made to prepare Fast dissolving Montelukast Sodium oral filmby solvent casting method. The fast dissolving films of Montelukast Sodium were prepared by solvent castingtechnique using film forming polymers HPMC E15 and Maltodextrin. The prepared film disintegrates withintwenty second which releases drug rapidly and gives antihypertensive action. As compared to that conventional dosage form, Fast dissolving Film has rapid onset of action. The optimized batch F4 was found to be stable for aperiod 1 months accelerated stability study at $40 \mathrm{oc} / 75 \% \mathrm{RH}$.

\section{REFERENCES}

1. PallaviPatil., S. K. Shrivastava. Fast Dissolving Oral Films: An Innovative DrugDeliverySystem.International Journal of Science and Research (IJSR), Volume 3 Issue 7, July 2014.

2. Priya Y D, Chaudhary Y A, Murthy T E G K, Seshagiri B. Approaches for taste masking of bitter drugs: a Review. Journal of Advances in Drug Research. 2011; (2): 58-67.

3. ParulSaini, Anoop Kumar, Pankaj Sharma, SharadVisht, Fast Disintegrating Oral Films: A Recent Trend of Drug Delivery International Journal of Drug Development \& Research, October-December 2012 , 4( 4), 80-94.

4. Lindgren S, Janzon L. Dysphagia: Prevalence of swallowing complaints and clinical findings. Medical Clinics of North America, (1993); 77: 3 -5.

5. Avery SW, Dellarosa DM. Approaches to treating dysphagia in patients with brain injury. Am. J. Occup.Ther. 1994; 48: 235.239

6. Kahrilas PJ. Anatomy, physiology and pathophysiology of dysphagia. Acta. Otorhinolaryngol Belg. 1994; 48: 97.117

7. Anderson $\mathrm{O}$. et al. Problems when swallowing tablets. TidsskrNorLaegeforen. 1995; 115: 947- 949

8. Naziyakhatoon, n. G. Raghavendrarao*, b. Mahipalreddy. Overview on fast dissolving oral films. International journal of Chemistry and Pharmaceutical sciences 2013, vol. 1(1):63-75

9. Ahmed MG, Narayana CR, Harish NM, Prabhakar P. Formulation and Invitro evaluation of Chitosan films containing tetracycline for the treatment of periodontitis. Asian J Pharm 2009; 3;113- 9.

10. HiroyoshiShimoda, Kazumi Taniguchi, Misao Nishimura, Katsuhiko Matsuura, TadaoTsukiokaHirotaka Yamashita, Naoki Inagaki, Kazuyuki Hirano, Mayumi Yamamoto YasutomiKinosada, Yoshinori Itoh Preparation of a fast dissolving oral thin film containing dexamethasone:A possible application to antiemesis during cancer chemotherapy Eur J Pharm and Biopharmaceutics 2009; 73; 361365 .

11. Rang HP, Dale MM., Ritter JM., Moore PK. Pharmacology. In Rang HP, 5th ed. Churchill Livingstone Publishing co. 2003; 236\&347.

12. FulzeleSV.,Sattuwar PM., Dorle AK. Polymerized rosin: novel film forming polymer for drug delivery. Int. J. Pharm. 2002; 249; 175-184.

13. K.vijaya sri1, p.rohini1 and g. Kamalakarreddy. Research article on montelukast sodium oral thin films: formulation and invitroevaluation. Asian journal of pharmaceutical and clinical research. Vol 5, suppl 4, 2012

14. Dixit RP.,Puthli SP., Oral strip technology: Overview and future potential , J of ContReleasen 2009 ;139: 94-107

15. Bradoo R. Fast Dissolving Drug Delivery Systems. JAMA India 2001; 4 (10): 27-31.

16. DebjitBhowmik, Chiranjib.B, Margret Chandira. Fast Dissolving Tablet: An Overview, Journal of Chemical and Pharmaceutical Research, 2009, 1(1): 163-177.

17. Arya A, Chandra A, Sharma V, Pathak K, Fast Dissolving Oral Films: An Innovative DrugDelivery System and Dosage Form, International Journal of ChemTech Research, 2010 2(1), 576-583.

18. Swapnil 1. Patil*, paresh r. Mahaparale, madhavi a. Shivnikar, shradha s. Tiwari, ketan v. Pawar, prashant $n$. Sane. Research article on fast dissolving oral films: an innovative drug delivery system.International journal of research and reviews in pharmacy and applied science 2(3).482-496,

19. Ketul, P.; Patel, K.; Patel, M.; Patel, N. Fast Dissolving Films: A Novel Approach to Oral Drug Delivery, International Journal of Pharmacy Teaching \& Practices, 2013, 4(2):655-661.

20. Galgatte, U.; Khanchandan, S.; Jadhav, Y.; Chaudhari, P. Investigation Of Different Polymers, Plasticizers And Superdisintegrating Agents Alone And In Combination For Use In The Formulation Of Fast Dissolving Oral Films, International Journal of PharmTech Research, 2013, 5 (4), 14651472.

21. Poonam A. Padamwar, Poonam P. Phasate. Formulation and evaluation of fast dissolving oral film of bisoprololfumarate. International journal of Pharma Sciences and Research vol 6 no 01 jan 2015.

22. Ketul, P.; Patel, K.; Patel, M.; Patel, N. Fast Dissolving Films: A Novel Approach to Oral Drug Delivery, International Journal of Pharmacy Teaching \& Practices, 2013, 4(2):655-661.

23. Khatoon N, Rao NGR. Formulation and evaluation oral fast dissolving film of Montelukast sodium, International Journal Of Pharmaceutical Sciences And Research, 2014, 5(5), 1780-1787.

24. AnjumPathan*, Mahesh Kumar Gupta, Neetesh Kumar Jain, AnkitaDubey, AnkitAgrawal. Research article :Formulation and evaluation of fast dissolving oral film of promethazine hydrochloride using different surfactant. Journal of Innovations in Pharmaceuticals and Biological Sciences Vol 3 (1), 74-84, 2016. 